\title{
First Trimester Diagnosis of Radial Ray Anomaly
}

\author{
Monica Kansal ${ }^{1}$ (D)
}

Received: 17 January 2020/ Accepted: 20 May 2020/Published online: 13 June 2020

(c) The Author(s) 2020

24 year old Primigravida with Dichorionic Diamniotic Twin Gestation.

She was complaining of intermittent spotting and came for a nuchal scan at 12 weeks 3 days. Previous scan done at 9 weeks revealed both viable embryos. Nuchal scan revealed mild CRL discordance between twins. Twin B was lagging with CRL corresponding to 11 weeks 5 days. Nuchal Translucency and Nasal Bone were normal in both fetuses. A detailed morphological survey was done for both.

Twin A was normal. Twin B was anomalous.

Twin B had unilateral upper limb defects with a single bone in the right forearm (Figs. 1, 2), fixed angulation deformity of the right wrist joint and absence of thumb in the right hand (Fig. 1). The findings were suggestive of Complete Radial Aplasia with Radial Club hand-Type IV Radial Ray anomaly.

This is frequently syndromic and is known to be associated with Trisomy 18, TAR syndrome, Holt Oram Syndrome, Robert's Syndrome and VACTERL association.

Additionally, presence of megacystis and single umbilical artery was noted in the affected fetus.

Combined First Trimester Screening was low risk for both the fetuses and the patient was referred to a Fetal
Medicine Unit in a Tertiary Care Hospital. A follow up scan done after 10 days confirmed the findings. In addition, the "Crash Sign" was found positive in the fetal brain and a hemivertebra was suspected in the fetal spine.

A complex non random combination of Multiple congenital malformations was observed and a diagnosis of VACTERL syndrome was made. No Invasive testing was done.

Patient was counselled and prognosticated regarding the defects. However Selective Termination of affected fetus was deferred in view of intermittent spotting. She was kept on Expectant management with follow up scans every 3-4 weeks.

Selective termination of the abnormal fetus was carried out with special permission at 28 weeks under special circumstances in view of spotting and high risk of miscarriage of normal fetus. She delivered a healthy child at 37 weeks by Cesarean Section (Indication: Breech Presentation). The terminated fetus delivered at the same time was macerated and the prenatal diagnosis of Unilateral Radial Ray Anomaly was confirmed (Figs. 3, 4). No Karyotype abnormality was noted in the abortus postnatally.
Monica Kansal

kaashiultrasoundclinic@gmail.com

1 Kaashi Ultrasound Clinic, FF - 17, Supertech Ecociti Mart, Sec 137, Noida, U.P, India 


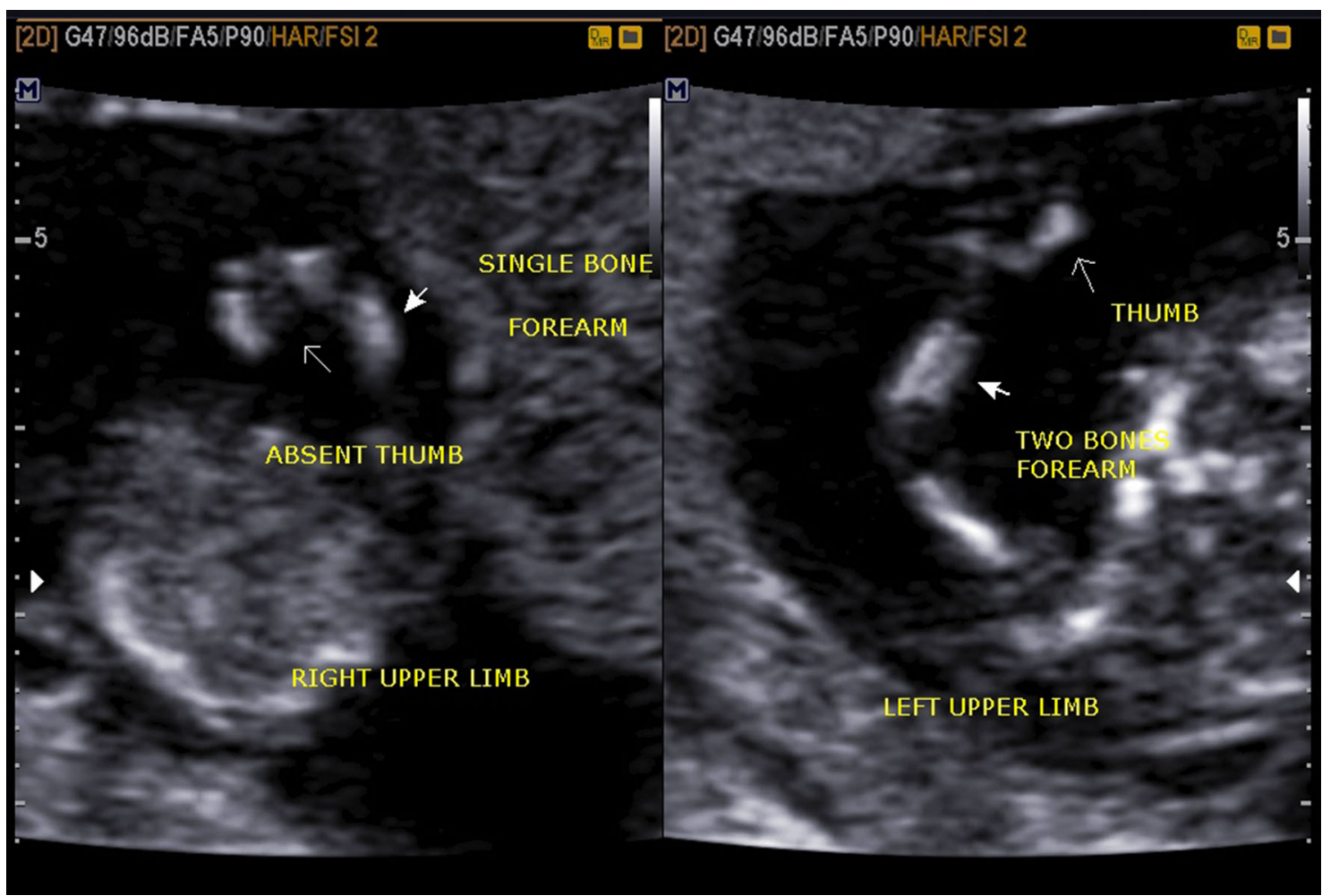

Fig. 1 Absence of Radius in Forearm (short bold arrow), radial deviation of hand with absent thumb (long arrow) noted in right upper limb; In contrast presence of both radius and ulna (short bold arrow) and normal thumb (long thin arrow) noted in left upper limb

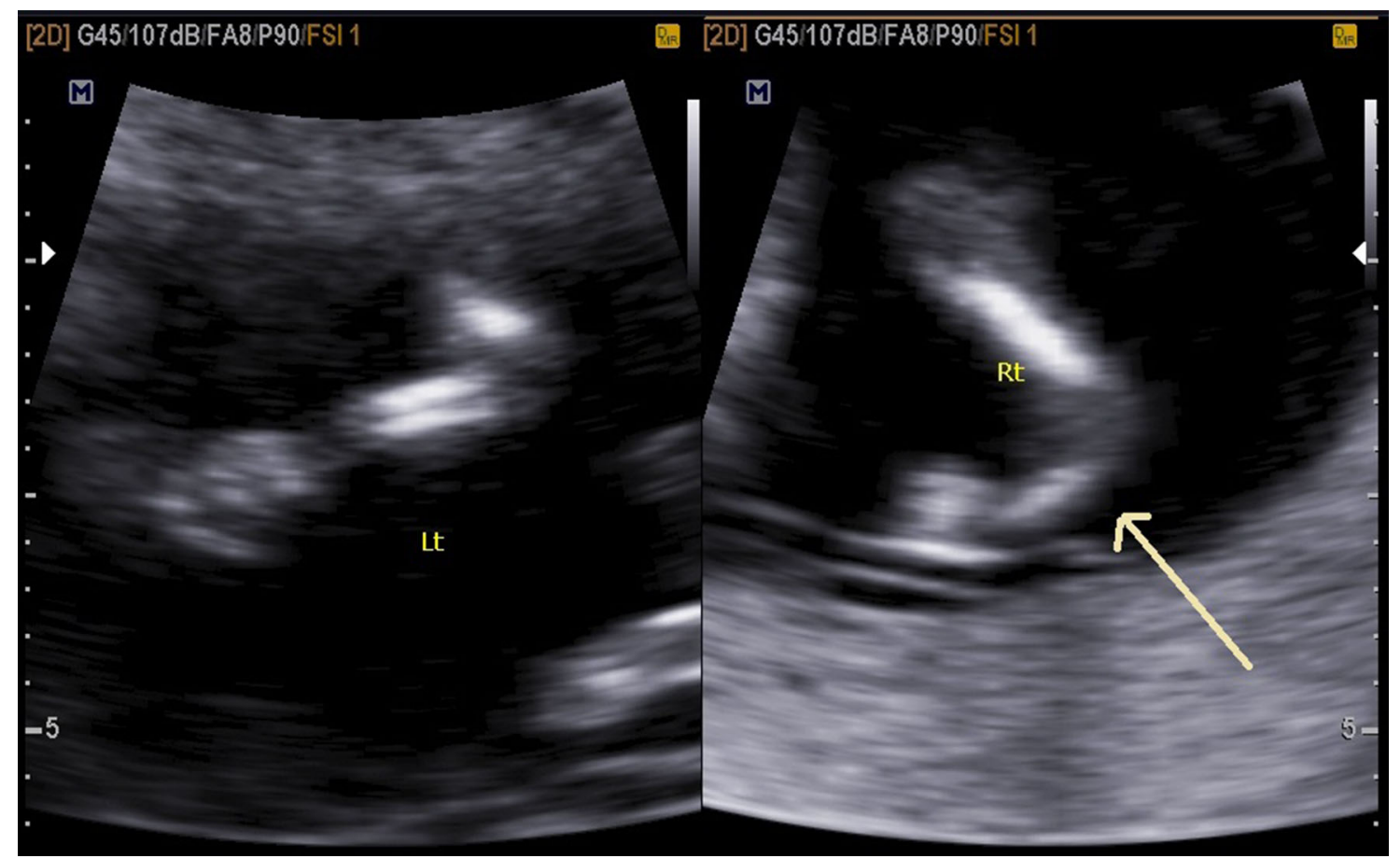

Fig. 2 Single bone seen in forearm in right upper extremity (arrow) 


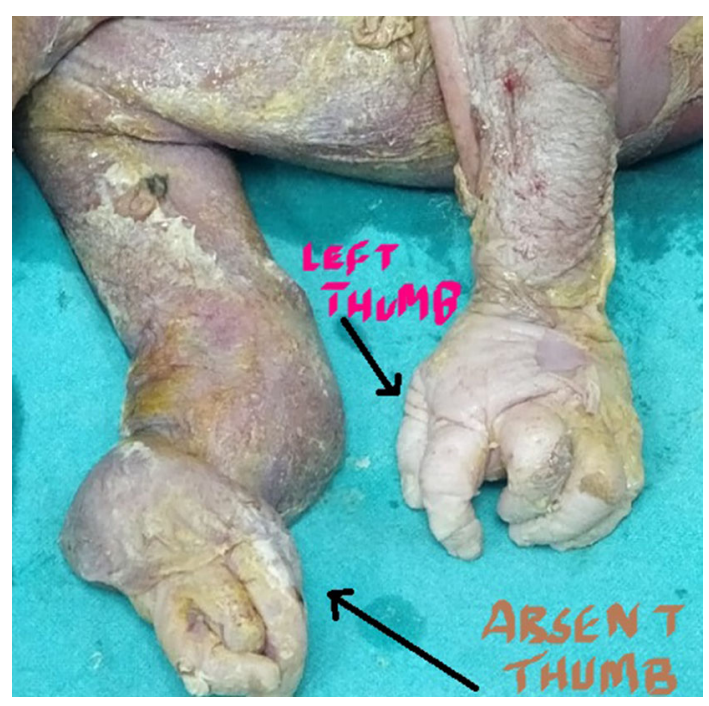

Fig. 3 Postnatal image of terminated fetus (long black arrow pointing towards absent thumb in right hand)

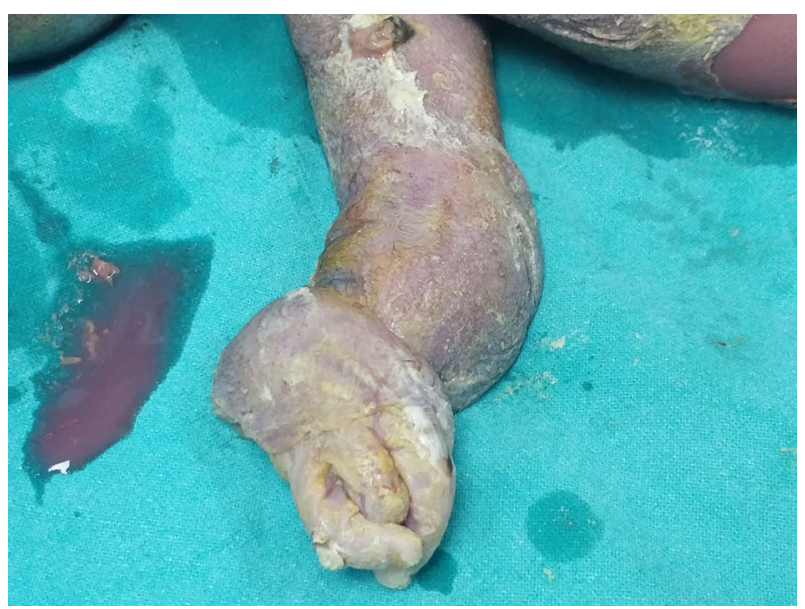

Fig. 4 Postnatal image of terminated fetus confirmed the diagnosis of unilateral radial ray anomaly
Open Access This article is licensed under a Creative Commons Attribution 4.0 International License, which permits use, sharing, adaptation, distribution and reproduction in any medium or format, as long as you give appropriate credit to the original author(s) and the source, provide a link to the Creative Commons licence, and indicate if changes were made. The images or other third party material in this article are included in the article's Creative Commons licence, unless indicated otherwise in a credit line to the material. If material is not included in the article's Creative Commons licence and your intended use is not permitted by statutory regulation or exceeds the permitted use, you will need to obtain permission directly from the copyright holder. To view a copy of this licence, visit http://creativecommons. org/licenses/by/4.0/.

Publisher's Note Springer Nature remains neutral with regard to jurisdictional claims in published maps and institutional affiliations. 